\title{
DESEMPENHO DE INDIVÍDUOS COM SÍNDROME DE DOWN NOS TESTES DE CONSCIÊNCIA FONOLÓGICAAPLICADOS COM E SEM APOIO VISUAL DE FIGURAS
}

\author{
Performance of individuals with Down's syndrome in tests of \\ phonological awareness applied with and without \\ visual support of illustrations
}

Ana Teresa de Mello Camuzzo Lara ${ }^{(1)}$, Silvia Helena de Rezende Trindade ${ }^{(2)}$, Katia Nemr ${ }^{(3)}$

\begin{abstract}
RESUMO
Objetivo: avaliar o desempenho dos indivíduos com Síndrome de Down, com e sem estímulo visual na consciência fonológica. Métodos: participaram 40 sujeitos com Síndrome de Down de ambos os sexos, que se encontravam em uma das fases do processo de apropriação da linguagem escrita, separados em dois grupos aleatórios, com números similares a partir das mesmas fases. Foram aplicadas nove provas de consciência fonológica do nível de sílaba do teste CONFIAS como proposto originalmente, no primeiro grupo e as mesmas provas adaptadas com figuras de apoio para todas as palavras, no segundo grupo. Resultados: os resultados mostraram que a média total de acerto dos 20 sujeitos que fizeram os testes com apoio visual de figuras é significativamente melhor se comparado com a média de acerto dos 20 sujeitos que fizeram o teste sem o apoio visual de figuras. Com o uso de figuras como apoio na avaliação da consciência fonológica, observou-se que os resultados referemse a real habilidade que o individuo apresenta sem a interferência de um possível déficit na memória auditiva de curto prazo. Conclusão: os achados permitem afirmar que, com $95 \%$ de probabilidade, a aplicação de figuras nos testes de consciência fonológica consiste em um benefício aos indivíduos com Síndrome de Down.
\end{abstract}

DESCRITORES: Síndrome de Down; Memória de Curto Prazo; Linguagem; Avaliação de Desempenho

\section{INTRODUÇÃO}

A expressão Consciência Fonológica refere-se à habilidade de lidar intencionalmente com as propriedades fonológicas da fala ${ }^{1}$.É descrita também como sendo a habilidade metalingüística que abrange a capacidade de refletir sobre os sons da fala e manipulálos ${ }^{2}$. Uma de suas definições refere ser a consciência de que as palavras são constituídas por uma seqüência de sons e desenvolve-se gradualmente durante a infância como parte da habilidade metalingüística, ou seja, a capacidade de pensar e

(1) Fonoaudióloga; Clínica Fonoaudiológica Lara; Especializanda em Linguagem.

(2) Fonoaudióloga; Prefeitura Municipal de São Paulo; Especializanda em Linguagem.

(3) Fonoaudióloga; Professora Concursada da Universidade de São Paulo; Doutora em Psicologia Social pela Universidade de São Paulo. refletir sobre a linguagem como um objeto ${ }^{3}$. Esta habilidade metalingüística é um dos mais importantes requisitos para a facilidade na aquisição da leitura, sendo causa e também condição necessária, porém não suficiente para o processo ${ }^{4}$.

Entre os pesquisadores, há atualmente um consenso da existência da relação de reciprocidade entre consciência fonológica e aquisição de leitura e escrita. A idéia é que a consciência fonológica contribui para o sucesso da aprendizagem da leitura e escrita, enquanto que a aprendizagem do sistema alfabético contribui para o desenvolvimento da consciência fonológica ${ }^{2,5,6}$.

As crianças com atraso em consciência fonológica, geralmente também apresentam atrasos de leitura e escrita ${ }^{1}$. Outros autores relatam em seus estudos que a correlação entre consciência fonológica e a leitura alfabética evidencia que crianças com problemas de leitura apresentam dificuldades em tarefas de consciência fonológica ${ }^{7}$. 
A ortografia de uma língua pode variar quanto ao tipo de correspondência fonema-grafema. Quando as correspondências são uniformes, constantes, com relações consistentes, sujeitas às regras segundo as quais, para cada grafema, equivale um único fonema e, para cada fonema, há um grafema que o represente, pode-se dizer que essa é uma ortografia do tipo transparente (como no português) ${ }^{8}$.

A aprendizagem da leitura alfabética requer, ao mesmo tempo, que o indivíduo compreenda que cada fonema corresponde a um grafema e que perceba que os fonemas e os grafemas obedecem a uma seqüência e ainda que qualquer modificação nesta seqüência resulte na produção de uma palavra diferente. Portanto, a aprendizagem da leitura e escrita do sistema de escrita alfabético pressupõe a habilidade de decompor e compor os sons da fala ${ }^{9}$.

Promover o desenvolvimento da consciência fonológica por meio de atividades que possibilitem a reflexão, a análise e síntese dos sons que compõem a fala são procedimentos importantes e que favorecem a aquisição da linguagem escrita ${ }^{10}$.

Transpondo estas considerações para o desenvolvimento da linguagem na criança com Síndrome de Down, pesquisas apontam que o comprometimento na memória de curto prazo, verificado nestes indivíduos, é considerado uma das causas do atraso cognitivo e do atraso no desenvolvimento da linguagem e também que a performance da memória de curto prazo para informações verbais é inferior do que para informações viso-espaciais ${ }^{11}$.

As alterações difusas, porém constantes das áreas sensoriais, associativas e pré-frontais do córtex cerebral são elementos primordiais do déficit cognitivo na Síndrome de Down ${ }^{12}$.

Na criança com Síndrome de Down, verifica-se um déficit mais marcante das competências lingüísticas em relação a outros aspectos do desenvolvimento. Em particular são descritos problemas no domínio da fonologia e da morfossintaxe e uma forte assincronia nas linhas de desenvolvimento referentes aos processos de produção em relação aos de compreensão, com maior desenvolvimento destes últimos ${ }^{13}$.

Denomina-se memória à aquisição, armazenamento e evocação de informações. A aquisição é também denominada de aprendizagem. É possível classificar as memórias de acordo com sua função, conteúdo e duração ${ }^{14}$. A memória de trabaIho se difere dos demais tipos de memória. Seu papel não é de formar arquivos e sim de analisar as informações que chegam constantemente ao cérebro e compará-las com as existentes nas demais memórias, dura segundos ou poucos minutos. Muitos reconhecem a memória de trabalho como o grande sistema "gerenciador" de informações do cérebro, já que ela "decide" que memórias serão formadas ou evocadas ${ }^{14}$. Já a memória de curta duração é aquela que dura poucas horas, justamente o tempo necessário para que as memórias de longa duração se consolidem ${ }^{14}$. Ela é essencial no aprendizado da linguagem e estaria particularmente envolvida no desenvolvimento lexical e no repertório das palavras. Se os mecanismos que permitem o funcionamento da memória de curto prazo estiverem alterados, uma das conseqüências será a dificuldade da criança em aprender palavras novas ${ }^{15}$.

Uma das pesquisas comparativas entre o funcionamento cerebral de indivíduos com Síndrome de Down com indivíduos sem a síndrome, mostrou que no cérebro das pessoas com a Síndrome estão comprometidas as partes responsáveis pelo funcionamento da memória auditiva de curto prazo e da memória auditiva espaço-temporal, mas estão preservados outros tipos de memória ${ }^{16}$.

Sendo assim sugere-se que sejam estimuladas formas de aprendizado que compensem as dificuldades de funcionamento do cérebro das crianças com Síndrome de Down, usando a memória visual como apoio à memória auditiva, mostrando elementos concretos como fotos, figuras, dentre outros, que representem as palavras ou frases faladas ${ }^{16}$.

Procedimentos para desenvolver consciência fonológica são instrumentos importantes que os profissionais podem usar para melhorar as habilidades de leitura e escrita, especialmente em crianças com atrasos de linguagem ${ }^{1}$.

O objetivo deste estudo é avaliar o desempenho dos indivíduos com Síndrome de Down com e sem estímulo visual na avaliação da consciência fonológica.

\section{MÉTODOS}

Participaram deste estudo 40 sujeitos com Síndrome de Down de ambos os sexos, com idades entre sete e 12 anos.

Foram excluídos por meio de dados de anamnese com os pais ou responsáveis, os sujeitos que apresentaram comprometimento de natureza auditiva que pudesse interferir no desempenho das provas.

Para cada individuo avaliado foi realizado um ditado de palavras e frases simples para a identificação da fase de apreensão do código escrito que se encontravam; pré-silábica, silábica, silábica-alfabética e alfabética ${ }^{17,18}$.

Dos 40 sujeitos que participaram da pesquisa, 12 estavam na fase pré-silábica, 18 estavam na fase silábica e dez na fase alfabética. Não foi encontrado nenhum sujeito que estivesse na fase silábica-alfabética. Os sujeitos foram divididos em dois grupos, aleatoriamente, em números iguais de participantes conforme a classificação da fase de alfabetização observada para receberem os estímulos sem figuras (Grupo 1) e com figuras (Grupo 2). 
De maneira aleatória foram aplicadas nove provas de consciência fonológica constantes do nível da sílaba do teste CONFIAS (Consciência Fonológica Instrumento de Avaliação Seqüencial) ${ }^{2}$ como proposto originalmente, porém sem as figuras para as palavras alvo sugeridas para as provas S3, S4, S6 e S7, no $1^{\circ}$ grupo, e as mesmas provas adaptadas com figuras de apoio para todas as palavras, no $2^{\circ}$ grupo.

Assim, os grupos foram constituídos da seguinte forma: dos 12 sujeitos que estavam na fase pré-silábica, seis sujeitos foram agrupados no grupo 1 e seis no grupo 2; dos 18 que mostraram estar na fase silábica, nove sujeitos constituíram o grupo 1 e nove o grupo 2, e dos dez na fase alfabética, cinco sujeitos ficaram no grupo 1 e outros cinco no grupo 2.

As figuras usadas para o grupo 2 estavam dispostas em uma folha de papel tamanho A4, com a figura correspondente à palavra alvo no centro superior e as figuras correspondentes às palavras alternativas dispostas em linha na parte inferior da mesma folha. Foi usada uma folha com figuras para cada uma das provas.

As provas do nível da sílaba foram: Síntese (S1), Segmentação (S2), Identificação da sílaba inicial (S3), Identificação de rima (S4), Produção da palavra com a sílaba inicial dada (S5), Identificação da sílaba medial (S6), Produção de rima (S7), Exclusão (S8) e Transposição (S9).

Os testes foram aplicados durante sessões individuais de aproximadamente 30 minutos cada, em consultório.

O projeto desta pesquisa foi avaliado e aprovado pelo Comitê de Ética em Pesquisa do CEFAC - Saúde e Educação, sob o número 213/05.

Para os resultados destas provas foi utilizado o programa SPSS (Statistical Package for Social Sciences), em sua versão 13.0. Considerou-se as médias de acertos, com os respectivos desvios-padrão. Na análise comparativa das médias de acertos entre os grupos, aplicou-se o Teste de Mann-Witney, considerando o nível de significância de 5\%.

\section{RESULTADOS}

A média total de acertos dos 20 sujeitos que fizeram os testes com o apoio visual de figuras foi de 29,60 pontos, tendo sido significantemente melhor quando comparada com a média de acertos dos 20 sujeitos que fizeram o teste sem o apoio visual de figuras, 16,65 pontos ( $p$-valor=0,001). Este dado mostra que há diferenças estatisticamente significantes entre os grupos considerados (Tabela 1). Na Tabela 1 é possível observar também que, além da média total, há melhoras (com a aplicação de figuras) observadas nos testes S1, S3, S4, S6 e S9. Esta comparação de performances pode também ser observada na Figura 1.

As comparações entre os grupos pré-silábico, silábico e alfabético mostraram os seguintes resultados:

\section{Pré-silábicos:}

Pode-se observar na Tabela 2, que no grupo présilábico a média total de acertos nos testes aplicados com figuras foi de 21,50 pontos, enquanto que a média de acertos obtida quando aplicados sem figuras foi de 7,67 pontos, com valor de $p=0,004$ mostrando que há diferenças estatisticamente significantes nos valores totais entre os grupos considerados.

Na Figura 2 observa-se a melhora no desempenho dos testes quando aplicados com o apoio de figuras por meio da comparação de performances médias no grupo dos pré-silábicos.

\section{Silábicos:}

Nos silábicos, assim como nos pré-silábicos, obteve-se um melhor desempenho nos sujeitos que foram avaliados com apoio de figuras. Pode-se observar na Tabela 3, que a média total de acertos quando o teste foi aplicado com figuras foi de 31,00 pontos enquanto que a média total de acertos quando aplicado sem figuras foi de 17,00 pontos, com valor de $p=0,001$, mostrando que há uma diferença estatisticamente significante entre os grupos considerados.

Na Figura 3, observa-se a melhora no desempenho nos testes quando aplicados com figuras por meio da comparação de performance média por teste no grupo dos silábicos.

\section{Alfabéticos:}

Como nas outras fases verificou-se que, com os sujeitos que se encontram na fase alfabética, o uso das figuras como apoio visual também resulta na melhora do desempenho. Pode-se observarna Tabela 4 que a média total de acertos quando os testes foram aplicados com figuras foi de 36,80 pontos, enquanto que a média de acertos quando aplicados sem figuras foi de 26,80 pontos com valor de $p=0,009$ mostrando assim uma diferença estatisticamente significante entre os grupos considerados.

Pode-se observar na Figura 4, a melhora no desempenho nos testes quando aplicados com figuras por meio da comparação de performance média por teste no grupo dos alfabéticos.

Observando-se as performances médias nos três grupos considerados, pré-silábico, silábico e alfabético, é possível verificar que há diferenças estatisticamente significantes nos valores totais, indicando melhora na performance dos testes quando a figura é usada como apoio visual.

Alguns testes individuais também demonstram efetiva melhora com o uso do apoio de figuras, por conta de apresentarem diferenças estatisticamente significantes entre os grupos considerados: pré-silábico: S3, S5 e S9 (Tabela 2); silábico: S1, S3, S4, S6, S7 e S9 (Tabela 3) alfabético: S4, S6 e S9 (Tabela 4). 
Tabela 1 - Comparação entre os grupos "sem e com figuras"

\begin{tabular}{|c|c|c|c|c|c|c|}
\hline Variável & Grupo & $\mathrm{n}$ & Média & Desvio-padrão & Diferença Percentual & Significância (p) \\
\hline \multirow{2}{*}{ S1 } & sem figuras & 20 & 2,80 & 1,40 & \multirow{2}{*}{$39,29 \%$} & \multirow{2}{*}{0,001} \\
\hline & com figuras & 20 & 3,90 & 0,45 & & \\
\hline \multirow{2}{*}{ S2 } & sem figuras & 20 & 2,80 & 1,51 & \multirow{2}{*}{$23,21 \%$} & \multirow{2}{*}{0,139} \\
\hline & com figuras & 20 & 3,45 & 1,10 & & \\
\hline \multirow{2}{*}{ S3 } & sem figuras & 20 & 1,65 & 1,50 & \multirow{2}{*}{$112,12 \%$} & \multirow{2}{*}{$<0,001$} \\
\hline & com figuras & 20 & 3,50 & 0,83 & & \\
\hline \multirow{2}{*}{ S4 } & sem figuras & 20 & 1,95 & 1,39 & \multirow{2}{*}{$71,79 \%$} & \multirow{2}{*}{0,001} \\
\hline & com figuras & 20 & 3,35 & 1,09 & & \\
\hline \multirow{2}{*}{ S5 } & sem figuras & 20 & 3,10 & 1,41 & \multirow{2}{*}{$22,58 \%$} & \multirow{2}{*}{0,148} \\
\hline & com figuras & 20 & 3,80 & 0,41 & & \\
\hline \multirow{2}{*}{ S6 } & sem figuras & 20 & 0,95 & 1,19 & \multirow{2}{*}{$189,47 \%$} & \multirow{2}{*}{$<0,001$} \\
\hline & com figuras & 20 & 2,75 & 1,37 & & \\
\hline \multirow{2}{*}{ S7 } & sem figuras & 20 & 0,65 & 0,67 & \multirow{2}{*}{$84,62 \%$} & \multirow{2}{*}{0,202} \\
\hline & com figuras & 20 & 1,20 & 1,24 & & \\
\hline \multirow{2}{*}{ S8 } & sem figuras & 20 & 2,15 & 2,46 & \multirow{2}{*}{$74,42 \%$} & \multirow{2}{*}{0,063} \\
\hline & com figuras & 20 & 3,75 & 2,81 & & \\
\hline \multirow{2}{*}{ S9 } & sem figuras & 20 & 0,60 & 1,05 & \multirow{2}{*}{$550,00 \%$} & \multirow{2}{*}{$<0,001$} \\
\hline & com figuras & 20 & 3,90 & 0,31 & & \\
\hline \multirow{2}{*}{ TOTAL } & sem figuras & 20 & 16,65 & 8,91 & \multirow{2}{*}{$77,78 \%$} & \multirow{2}{*}{$<0,001$} \\
\hline & com figuras & 20 & 29,60 & 6,95 & & \\
\hline
\end{tabular}

Teste estatístico de Mann-Whitney.

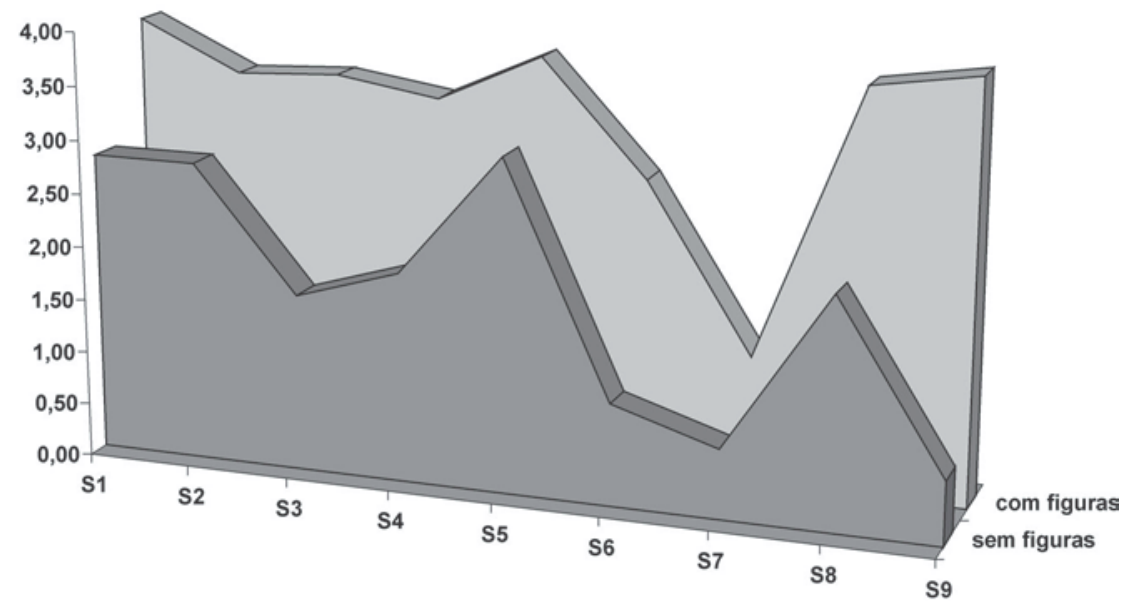

$\square$ sem figuras $\square$ com figuras

Figura 1 - Comparação de performance média total por teste, com e sem figuras 
Tabela 2 - Grupo dos pré silábicos

\begin{tabular}{|c|c|c|c|c|c|c|}
\hline Variável & Grupo & $\mathrm{n}$ & Média & Desvio-padrão & $\begin{array}{l}\text { Diferença } \\
\text { Percentual }\end{array}$ & $\begin{array}{c}\text { Significância } \\
\text { (p) }\end{array}$ \\
\hline \multirow{2}{*}{ S1 } & pré-silábico (sem figura) & 6 & 1,83 & 1,83 & \multirow{2}{*}{$100,00 \%$} & \multirow{2}{*}{0,060} \\
\hline & pré-silábico (com figura) & 6 & 3,67 & 0,82 & & \\
\hline \multirow{2}{*}{ S2 } & pré-silábico (sem figura) & 6 & 1,33 & 1,51 & \multirow{2}{*}{$112,50 \%$} & \multirow{2}{*}{0,138} \\
\hline & pré-silábico (com figura) & 6 & 2,83 & 1,60 & & \\
\hline \multirow{2}{*}{ S3 } & pré-silábico (sem figura) & 6 & 0,50 & 1,22 & \multirow{2}{*}{$500,00 \%$} & \multirow{2}{*}{0,011} \\
\hline & pré-silábico (com figura) & 6 & 3,00 & 1,10 & & \\
\hline \multirow{2}{*}{ S4 } & pré-silábico (sem figura) & 6 & 1,50 & 1,38 & \multirow{2}{*}{$44,44 \%$} & \multirow{2}{*}{0,284} \\
\hline & pré-silábico (com figura) & 6 & 2,17 & 1,33 & & \\
\hline \multirow{2}{*}{ S5 } & pré-silábico (sem figura) & 6 & 2,17 & 1,60 & \multirow{2}{*}{$76,92 \%$} & \multirow{2}{*}{0,049} \\
\hline & pré-silábico (com figura) & 6 & 3,83 & 0,41 & & \\
\hline \multirow{2}{*}{ S6 } & pré-silábico (sem figura) & 6 & 0,00 & 0,00 & \multirow{6}{*}{$100,00 \%$} & \multirow{2}{*}{0,058} \\
\hline & pré-silábico (com figura) & 6 & 1,17 & 1,33 & & \\
\hline \multirow{2}{*}{ S7 } & pré-silábico (sem figura) & 6 & 0,33 & 0,52 & & \multirow{2}{*}{0,138} \\
\hline & pré-silábico (com figura) & 6 & 0,00 & 0,00 & & \\
\hline \multirow{2}{*}{ S8 } & pré-silábico (sem figura) & 6 & 0,00 & 0,00 & & \multirow{2}{*}{0,056} \\
\hline & pré-silábico (com figura) & 6 & 1,00 & 1,10 & & \\
\hline \multirow{2}{*}{ S9 } & pré-silábico (sem figura) & 6 & 0,00 & 0,00 & \multirow{4}{*}{$180,43 \%$} & \multirow{2}{*}{0,001} \\
\hline & pré-silábico (com figura) & 6 & 3,83 & 0,41 & & \\
\hline \multirow{2}{*}{ TOTAL } & pré-silábico (sem figura) & 6 & 7,67 & 1,37 & & \multirow{2}{*}{0,004} \\
\hline & pré-silábico (com figura) & 6 & 21,50 & 5,32 & & \\
\hline
\end{tabular}

Teste estatístico de Mann-Whitney.

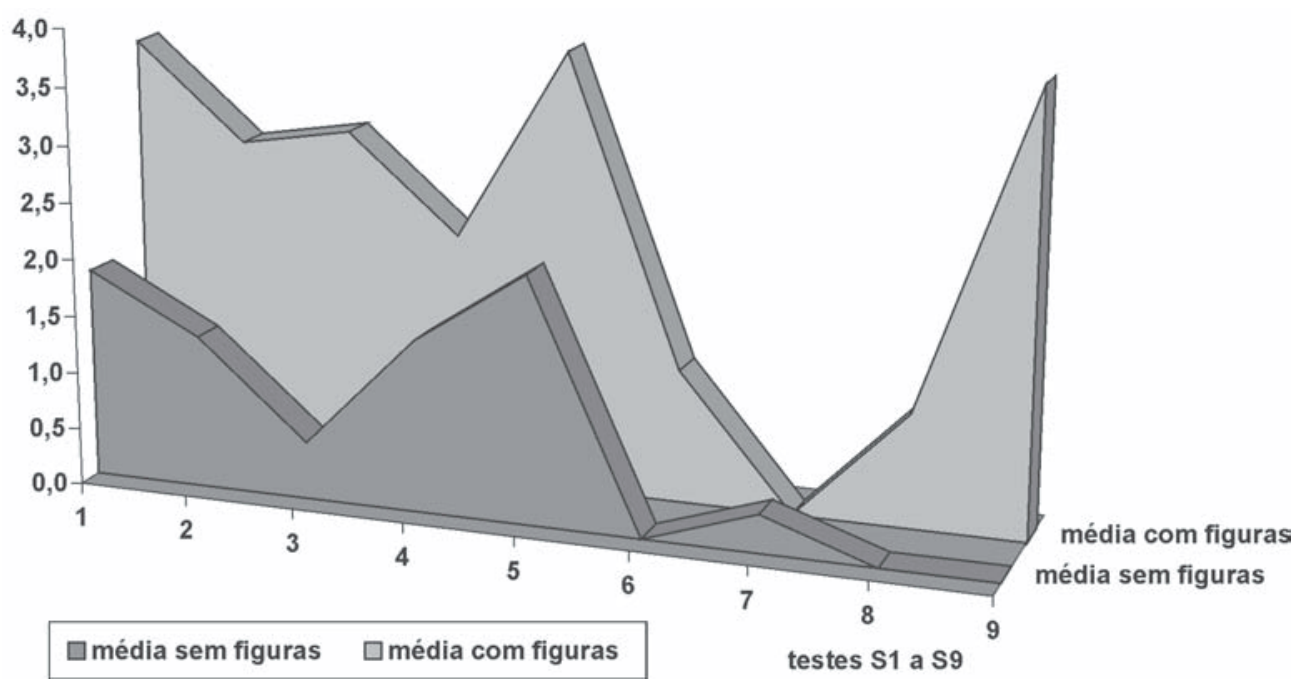

Figura 2 - Comparação de performance média por teste, com e sem figuras, de acordo com o nível de alfabetização: pré-silábicos 
Tabela 3 - Grupo dos silábicos

\begin{tabular}{|c|c|c|c|c|c|c|}
\hline Variável & Grupo & $\mathbf{n}$ & Média & Desvio-padrão & $\begin{array}{l}\text { Diferença } \\
\text { Percentual }\end{array}$ & $\begin{array}{l}\text { Significância } \\
\text { (p) }\end{array}$ \\
\hline \multirow{2}{*}{ S1 } & silábico (sem figura) & 9 & 2,78 & 0,97 & \multirow{2}{*}{$44,00 \%$} & \multirow{2}{*}{0,001} \\
\hline & silábico (com figura) & 9 & 4,00 & 0,00 & & \\
\hline \multirow{2}{*}{ S2 } & silábico (sem figura) & 9 & 3,11 & 1,17 & \multirow{2}{*}{$14,29 \%$} & \multirow{2}{*}{0,340} \\
\hline & silábico (com figura) & 9 & 3,56 & 0,88 & & \\
\hline \multirow{2}{*}{ S3 } & silábico (sem figura) & 9 & 1,56 & 1,24 & \multirow{2}{*}{$128,57 \%$} & \multirow{2}{*}{0,003} \\
\hline & silábico (com figura) & 9 & 3,56 & 0,73 & & \\
\hline \multirow{2}{*}{ S4 } & silábico (sem figura) & 9 & 1,44 & 1,24 & \multirow{2}{*}{$161,54 \%$} & \multirow{2}{*}{0,001} \\
\hline & silábico (com figura) & 9 & 3,78 & 0,44 & & \\
\hline \multirow{2}{*}{ S5 } & silábico (sem figura) & 9 & 3,22 & 1,39 & \multirow{2}{*}{$13,79 \%$} & \multirow{2}{*}{0,751} \\
\hline & silábico (com figura) & 9 & 3,67 & 0,50 & & \\
\hline \multirow{2}{*}{ S6 } & silábico (sem figura) & 9 & 1,00 & 0,87 & \multirow{2}{*}{$211,11 \%$} & \multirow{2}{*}{$<0,001$} \\
\hline & silábico (com figura) & 9 & 3,11 & 0,60 & & \\
\hline \multirow{2}{*}{ S7 } & silábico (sem figura) & 9 & 0,56 & 0,73 & \multirow{2}{*}{$180,00 \%$} & \multirow{2}{*}{0,042} \\
\hline & silábico (com figura) & 9 & 1,56 & 1,13 & & \\
\hline \multirow{2}{*}{ S8 } & silábico (sem figura) & 9 & 2,33 & 1,94 & \multirow{2}{*}{$66,67 \%$} & \multirow{2}{*}{0,119} \\
\hline & silábico (com figura) & 9 & 3,89 & 2,26 & & \\
\hline \multirow{2}{*}{ S9 } & silábico (sem figura) & 9 & 1,00 & 1,32 & \multirow{2}{*}{$288,89 \%$} & \multirow{2}{*}{0,001} \\
\hline & silábico (com figura) & 9 & 3,89 & 0,33 & & \\
\hline \multirow{2}{*}{ TOTAL } & silábico (sem figura) & 9 & 17,00 & 6,91 & \multirow{2}{*}{$82,35 \%$} & \multirow{2}{*}{$<0,001$} \\
\hline & silábico (com figura) & 9 & 31,00 & 3,32 & & \\
\hline
\end{tabular}

Teste estatístico de Mann-Whitney.

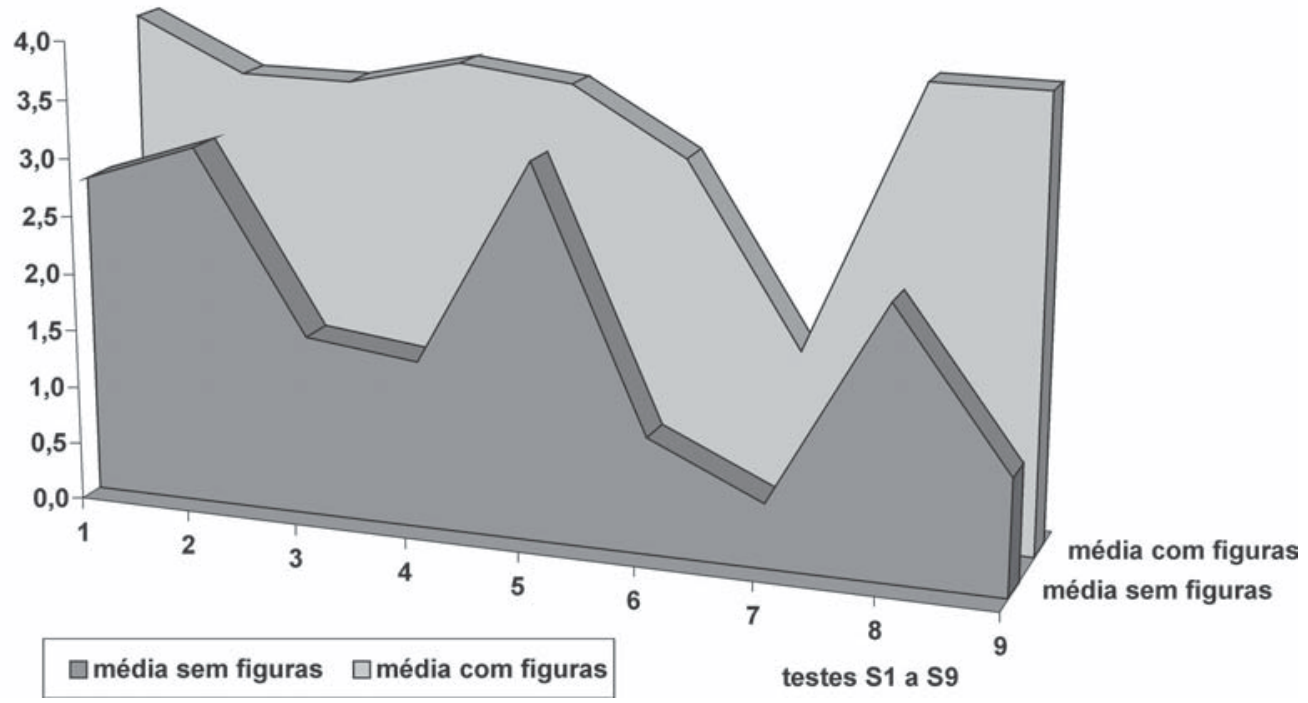

Figura 3 - Comparação de performance média por teste, com e sem figuras, de acordo com o nível de alfabetização: silábicos 
Tabela 4 - Grupo dos alfabéticos

\begin{tabular}{|c|c|c|c|c|c|c|}
\hline Variável & Grupo & $\mathrm{n}$ & Média & Desvio-padrão & $\begin{array}{c}\text { Diferença } \\
\text { Percentual }\end{array}$ & $\begin{array}{l}\text { Significância } \\
\text { (p) }\end{array}$ \\
\hline \multirow{2}{*}{ S1 } & alfabético (sem figura) & 5 & 4,00 & 0,00 & \multirow{2}{*}{$0,00 \%$} & \multirow{2}{*}{$>0,999$} \\
\hline & alfabético (com figura) & 5 & 4,00 & 0,00 & & \\
\hline \multirow{2}{*}{ S2 } & alfabético (sem figura) & 5 & 4,00 & 0,00 & \multirow{2}{*}{$0,00 \%$} & \multirow{2}{*}{$>0,999$} \\
\hline & alfabético (com figura) & 5 & 4,00 & 0,00 & & \\
\hline \multirow{2}{*}{ s3 } & alfabético (sem figura) & 5 & 3,20 & 0,84 & \multirow{2}{*}{$25,00 \%$} & \multirow{2}{*}{0,053} \\
\hline & alfabético (com figura) & 5 & 4,00 & 0,00 & & \\
\hline \multirow{2}{*}{ S4 } & alfabético (sem figura) & 5 & 3,40 & 0,55 & \multirow{2}{*}{$17,65 \%$} & \multirow{2}{*}{0,049} \\
\hline & alfabético (com figura) & 5 & 4,00 & 0,00 & & \\
\hline \multirow{2}{*}{ S5 } & alfabético (sem figura) & 5 & 4,00 & 0,00 & \multirow{2}{*}{$0,00 \%$} & \multirow{2}{*}{$>0,999$} \\
\hline & alfabético (com figura) & 5 & 4,00 & 0,00 & & \\
\hline \multirow{2}{*}{ S6 } & alfabético (sem figura) & 5 & 2,00 & 1,58 & \multirow{2}{*}{$100,00 \%$} & \multirow{2}{*}{0,019} \\
\hline & alfabético (com figura) & 5 & 4,00 & 0,00 & & \\
\hline \multirow{2}{*}{ S7 } & alfabético (sem figura) & 5 & 1,20 & 0,45 & \multirow{2}{*}{$66,67 \%$} & \multirow{2}{*}{0,189} \\
\hline & alfabético (com figura) & 5 & 2,00 & 1,22 & & \\
\hline \multirow{2}{*}{ S8 } & alfabético (sem figura) & 5 & 4,40 & 2,79 & \multirow{2}{*}{$54,55 \%$} & \multirow{2}{*}{0,105} \\
\hline & alfabético (com figura) & 5 & 6,80 & 1,64 & & \\
\hline \multirow{2}{*}{ s9 } & alfabético (sem figura) & 5 & 0,60 & 0,89 & \multirow{2}{*}{$566,67 \%$} & \multirow{2}{*}{0,005} \\
\hline & alfabético (com figura) & 5 & 4,00 & 0,00 & & \\
\hline \multirow{2}{*}{ TOTAL } & alfabético (sem figura) & 5 & 26,80 & 5,40 & \multirow{2}{*}{$37,31 \%$} & \multirow{2}{*}{0,009} \\
\hline & alfabético (com figura) & 5 & 36,80 & 2,17 & & \\
\hline
\end{tabular}

Teste estatístico de Mann-Whitney.

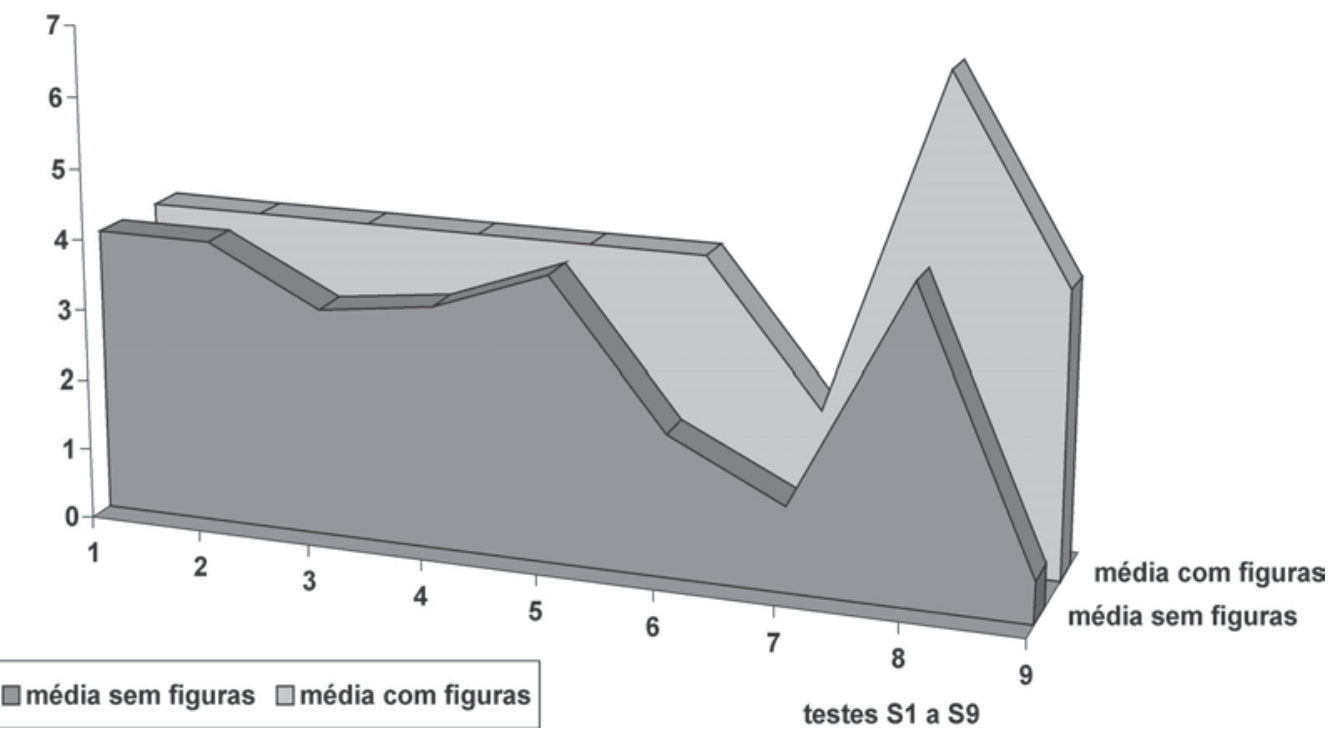

Figura 4 - Comparação de performance média por teste, com e sem figuras, de acordo com o nível de alfabetização: alfabéticos 


\section{DISCUSSÃO}

Há ampla evidência de que o treinamento da consciência fonológica exerce um impacto positivo na aprendizagem da leitura e escrita ${ }^{19}$. O sistema de escrita alfabético pressupõe a habilidade de compor e decompor os sons da fala ${ }^{9}$. A reflexão, a análise e síntese dos sons que compõem a fala são procedimentos importantes que favorecem a aquisição da linguagem escrita ${ }^{10}$. A habilidade de crianças em idade pré-escolar de prestar atenção consciente aos sons da fala prevê o progresso que elas apresentam, anos mais tarde, na aprendizagem da leitura e da escrita ${ }^{20}$.

No presente estudo, na análise dos sujeitos com Síndrome de Down avaliados com figuras, foi encontrado $74 \%$ de acertos e nos avaliados sem figuras, $42 \%$ de acertos. Como se pode verificar, os indivíduos com Síndrome de Down apresentaram um desempenho melhor nos testes de Consciência Fonológica quando estes foram aplicados com o apoio visual de figuras. Isto pode ser explicado pelo fato de os indivíduos com Síndrome de Down apresentarem uma capacidade de memória auditiva de curto prazo mais breve, o que pode dificultar o acompanhamento de instruções faladas, especialmente se elas envolverem múltiplas informações ou ordens/ orientações consecutivas. Esta dificuldade pode, entretanto, ser minimizada se estas instruções forem acompanhadas por gestos ou figuras que se refiram as instruções dadas ${ }^{21}$, sendo necessário mostrar elementos concretos que representem as palavras ou frases faladas ${ }^{16}$.

No mesmo sentido, por apresentarem habilidades de processamento e de memória visual mais desenvolvidas do que aquelas referentes às capacidades de processamento e memória auditiva, os indivíduos com Síndrome de Down se beneficiarão de recursos de ensino que utilizem suporte visual para trabalhar as informações ${ }^{21}$.

Com o uso de figuras como apoio na avaliação da Consciência Fonológica, pode-se garantir que os resultados obtidos referem-se a real habilidade que o individuo apresenta sem a interferência de um possível déficit na memória auditiva de curto prazo. As médias encontradas entre os sujeitos com Síndrome de Down que foram avaliados com apoio visual de figuras foram próximas das médias esperadas em cada fase de alfabetização referidas pelo teste CONFIAS.

Observa-se nesta pesquisa que os indivíduos que foram avaliados sem o apoio de figuras, em alguns testes, enquanto analisavam as unidades sonoras de uma palavra, já haviam esquecido a instrução inicial solicitada, ou as outras palavras que compunham o teste, prejudicando assim seu desempenho.

Outra evidência de que a figura pode eliminar a interferência do déficit na memória de curto prazo, pode ser constatada ao observar que, nos testes aplicados sem figura, onde o indivíduo deveria escolher uma entre três palavras ditas, houve uma tendência a repetir a última palavra da série das três (por ser a última), levando a erros e acertos que podem não mostrar fielmente a real capacidade ou habilidade deste individuo.

No teste de identificação de rima (S4) ficou evidente que o uso de figuras foi um facilitador para a execução adequada da prova. No entanto, na prova de produção de rima (S7), o uso de figuras mostrouse irrelevante, pois a prova não exigia o resgate da memória auditiva e sim uma produção espontânea que requer uma sensibilidade prévia da rima e esta sim poderá ser estimulada usando o apoio de figuras favorecendo o melhor desenvolvimento da consciência fonológica.

A sensibilidade à rima implica uma capacidade para detectar estruturas sonoras semelhantes em diferentes palavras. Embora não seja considerado como um conhecimento fonológico propriamente dito, acredita-se que tal noção possibilite um melhor desenvolvimento da consciência fonológica, assim como venha auxiliar a aprendizagem futura da leitura, principalmente em termos de facilitar estratégias de leitura por analogia ${ }^{17}$.

A idéia da relação de reciprocidade entre consciência fonológica e aquisição de leitura e escrita ${ }^{2}$ é notada ao se verificar neste estudo que houve uma visível melhora no número de pontos obtidos nos testes ao se comparar os indivíduos da fase pré-silábica para silábica e depois alfabética. $\mathrm{O}$ uso de figuras com os indivíduos na fase alfabética aponta uma melhora no desempenho de algumas provas específicas como S4, S6 e S9. Porém, geralmente, apresentam um bom desempenho nestes testes mesmo sem o uso de figuras. $\mathrm{O}$ fato da presença de figuras não ser tão relevante nesta fase, não significa que se deve excluir o apoio visual para esses sujeitos, pois os dados obtidos sinalizam que não só o trabalho de estimulação da consciência fonológica, mas também a estimulação da linguagem como um todo nos sujeitos com Síndrome de Down será mais eficiente se for usado o apoio visual por meio de figuras.

Considerando-se que, sendo a informação auditiva no indivíduo com Síndrome de Down menos eficaz que a visual ${ }^{11}$, torna-se necessário usar duas ou mais vias para que a informação possa ser assimilada ${ }^{22}$. Sendo assim, o aspecto mais relevante desta pesquisa foi o de apontar a importância do uso de figuras no trabalho que tenha como objetivo o desenvolvimento das percepções auditivas e da aprendizagem como um todo nos sujeitos com Síndrome de Down.

É imprescindível que aos indivíduos com Síndrome de Down seja dada toda oportunidade de aprendizagem, usando para isto todas as vias perceptivas, garantindo assim seu desenvolvimento. 


\section{CONCLUSÃO}

Os resultados alcançados neste estudo permitem afirmar que o uso de figuras beneficia a estimulação da Consciência Fonológica em indivíduos com Síndrome de Down, permitindo um melhor desempenho no processo de aquisição da leitura e escrita.

\begin{abstract}
Purpose: this study aims at assessing the performance of individuals with Down's Syndrome when phonological awareness is stimulated with illustrations or not. Methods: the study involved 40 subjects with Down's Syndrome, of both genders, and still in one of the phases of written language acquisition, separated in two random groups, with similar numbers starting from the same phases. A group of twenty subjects did nine tests of the syllable level CONFIAS test for phonological awareness. The second group of twenty did the version of the same test with the adaptation of illustrations. Results: the results revealed that the total average score of the 20 subjects who did the adapted test was significantly higher than the performance of the other 20 who did the test without illustrations. The use of such visual elements as a support in the assessment of phonological awareness led us to conclude that the results show individual's real ability without the interference of a possible short-term hearing memory deficit. Conclusion: the results allow us to state that there is a $95 \%$ probability of benefit to individuals with Down's Syndrome when illustrations are used in the tests of phonological awareness.
\end{abstract}

KEYWORDS: Down Syndrome; Memory Short-Term Language; Employee Performance Appraisal

\section{REFERÊNCIAS}

1.Capovilla AGS, Capovilla FC. Problema de leitura e escrita: como identificar, prevenir e remediar numa abordagem fônica. São Paulo: Memnon; 2000. p. 1. 2.Moojen S, Lamprecht R, Santos RM, Freitas GM, Brodacz R, Siqueira M, et al. CONFIAS: consciência fonológica: instrumento de avaliação seqüencial. São Paulo: Casa do Psicólogo; 2003. p. 11-2.

3.Capellini SA, Ciasca SM. Avaliação da consciência fonológica em crianças com distúrbio específico da leitura e distúrbio de aprendizagem. Temas Sobre Desenvolv. 2000; 17:23-8.

4.Stanovich K. Romance and reality: distinguished educator series. Reading Teacher. 1994; 47:280-91.

5.Content A. L'analyse phonetique explecite de la parole et l'acquisition de la lecture. L'anneé Psychologique. 1984; 84:555-72.

6.Perfetti C, Beck I, Ball L, Hughes C. Phonemic knowledge and learning to read are reciprocal: a longitudinal study of first grade children. Merril-Palmer Quarterly. 1987; 33:283-319.

7.Bradley L, Bryant P. Difficulties in auditory organisation as a possible cause of reading backwardness. Nature. 1978; 271(5647):746-7.

8.Godoy DM. O papel da consciência fonológica no processo de alfabetização. Pró-Fono. 2003; 15:241-50.

9.Soares MB, Martins CC. A consciência fonológica de crianças das classes populares: o papel da escola. Rev Bras Est Pedag. 1989; 70:86-97.

10. Maluf MR, Barrera SD. Consciência fonológica e linguagem escrita em pré-escolares. Psicol Refl Crít. 1997; 10:125-45.

11. Kanno K, Ikeda Y. Word-length effect in verbal short-term memory in individuals with Down's syndrome. J Intellect Disabil Res. 2002; 46(8):613-18.

12. Flórez J. Patologia cerebral y aprendizaje en el síndrome de Down. In: Flórez J, Troncoso MV. Síndrome de Down y educación. Barcelona: Masson; 1991. p. 51.

13. Chilosi AM. Lo sviluppo del linguaggio. In: Bargagna $\mathrm{S}$, Massei F. Un progetto integrato pel la síndrome di Down. Pisa: Del Cerro; 1996. p. 117-23.

14. Izquierdo I. Memória. Porto Alegre: Artmed; 2002. p. 20-51.

15. Brizzolara D. Lo sviluppo della memoria. In: Bargagna S, Massei F. Un progetto integrato pel la sindrome di Down. Pisa: Del Cerro; 1996. p. 111-5. 16. Hodapp R. Novas abordagens no trabalho com síndrome de Down. VI Congresso Mundial de Síndrome de Down: 1997; out, Espanha.

17. Zorzi JL. Aprendizagem e distúrbios da linguagem escrita: questões clínicas e educacionais. São Paulo: Artmed; 2003. p. 29.

18. Alegria J. Análisis segmental y adquisición de la lectura a propósito de lo que el niño sabe y de lo que ignora quando comienzan a enseñarle a 
leer. Leng Comun. 1993; 8:13-22.

19. O'Connor R, Jeenkins J, Slocum T. Transfer among phonological tasks in kidergarten: essential instructional content. J Educ Psychol. 1985; 87:202-17.

20. Wimmer H, Landerl K, Linortner R, Hummer P.The relationship of phonemic awareness to reading acquisition: more consequence than precondition but still important. Cognition. 1991; 40(3):219-49.

21. Bissoto ML. O desenvolvimento cognitivo e o processo de aprendizagem do portador de síndrome de Down: revendo concepções e perspectivas educacionais. Ciênc Cognição. 2005; 2(4):80-8.

22. Mills ND. A educação da criança com síndrome de Down. In: Schwartzman JS. Síndrome de Down. São Paulo: Memnon; 1999; p. 247.

RECEBIDO EM: 05/10/2006

ACEITO EM: 06/05/2007

Endereço para correspondência:

Al. Joaquim Eugênio de Lima,1286

São Paulo - SP

CEP: 01403-002

Tel: (11) 38877062

E-mail:an.teresa@bol.com.br

sihrt@ig.com.br 